\title{
FOCUS ON THE TRANSLATION TRAINEE
}

\author{
Paulina Pietrzak \\ University of Łódź, Poland \\ paulina.pietrzak@uni.lodz.pl \\ MICHAE KORNACKI \\ University of Łódź, Poland \\ michal.kornacki@uni.lodz.pl
}

\begin{abstract}
A learner-based approach to translator training has already been recognised and discussed in translator education for the last few years (González-Davies 2004; Kelly 2005; Kiraly 1995, 2000; Massey et al. 2019). With the main focus on learning rather than training and the translator rather than the product or the process of translation, the observed trend in translation studies can be called 'translator studies' (Chesterman 2009). The tendency has been for the teacher-centred approach to be gradually replaced by manners of teaching which favour learner autonomy (Gonzalez Davies 2004).

Nonetheless, due to the multiple demands that translator teachers must fulfil, they still happen to be regarded as the main active performers in the educational process. Invaluable as the teacher's agency is for shaping the educational reality that translation trainees experience, translator education requires ensuring that student-oriented education actually involves freeing teachers and students from their traditional roles, to break out of the routine in which they have been rooted for years. It is worth emphasising that the roles and responsibilities of the translator teacher and student are equally important. The article looks at the translation educational process with the main focus on trainees who are supposed to build their career in the uncertain and indeterminate translation industry of the future.
\end{abstract}

\section{Breaking out of the training routine into new learning routines}

The main two approaches to translator education seem to be mutually exclusive, with the teacher-oriented transmissionist approach on one side and learneroriented approach on the other, so radically different with its socio-constructivist principles and situated collaborative environments (González-Davies and Enríquez 2018). Since the main assumption behind translator education is no longer just the transfer of content knowledge, holistic approaches to translator education go beyond this binary choice between transmissionist (teachercentered) and transactional (learner-centered, based on teacher-assisted 
knowledge construction). The aim behind truly practical and comprehensive approaches is to elicit a transformation of the translation trainee (see Klimkowski 2015).

In the transformative approach, learning is seen as inducing change in the learner and, as observed by Mezirow (2003: 58-59) transforming "problematic frames of reference-sets of fixed assumptions and expectations (habits of mind, meaning perspectives, mindsets) - to make them more inclusive, discriminating, open, reflective, and emotionally able to change". Under the transformative view on learning, both translation teachers and students take active part in the process of perspective transformation and they all develop together through educational interaction.

The idea of learning as a perspective transformation (see Boyd and Myers 1988, Cranton 1994, Mezirow 1990, 1996, 2003) assumes that learners not only acquire skills but change holistically. Transformation cannot be defined here "in terms of a curricular objective" (Klimkowski 2015: 90) since it "cannot be measured by a grid or a grading scale, and, in fact, it can hardly be defined as a skill or competence". As Klimkowski further observes (ibid.) "the power of transformative education is more accessible to those classroom formats which are ready to recognize the role of human knowledge constructors - learners and teachers - who meet in order to support each other's holistic growth". The holistic stance on learning puts emphasis on the human potential and personal resources of the learner.

\section{Personal resources in translator education}

What seems to be critical in the face of all the dynamic changes in the translation market is adaptability and personal resources of the translator. Personal resources are understood here as aspects of the self that make up the psychological capital of the translator and relate to the sense of being able to successfully meet job demands (Pietrzak 2022 forth.). Given that we can expect rather unpredictable market needs, activating personal resources can potentially enable trainee translators to further develop and operate effectively in such an uncertain market situation.

The training that focuses on personal resources often provides translation students with no particular content, but rather focuses on learning strategies and fostering the students' sense of self. Since in the transformative translator training, it is the trainee and his or her personal agency that is in the centre of educational attention. Personal resources can be regarded as factors of the self (Hobfoll, 2002, 2003), social and psychological assets (Lin 2017) or, as exemplified by Hobfoll et al. (2018: 105), "key skills and personal traits such as self-efficacy".

It needs to be taken into account that students who are supposed to enter the postpandemic translation market must be ready for continuous self-development, 
adapting to the changing conditions and self-directed lifelong learning. Among many approaches that seem particularly effective here are, for instance, situated learning, self-directed learning, reflective practice, experiential learning, metacognitive translator training, etc.

In situated learning, i.e. "a context-dependent approach to translator or interpreter training [...] learners are exposed to real-life and/or highly simulated work environments and tasks, both inside and outside the classroom" (GonzálezDavies and Enriquez 2018: 1). As González Davies observes (in this special issue), "collaborative and situated environments are especially favourable to the development of autonomous strategic learning". In the situated approach the construction of knowledge is placed in students' hands, which makes them more accountable for their learning process. The equal sharing of roles and responsibilities lays the foundation for translator education aimed at the development of student agency and autonomy.

Another approach listed above is the self-directed approach which assumes that learning can be described as a process in which students "will experience anxiety, frustration, and often failure, and so will their teachers" (Knowles 1975: 14). Teachers no longer have their "protective shield of an authority figure" and show their students that they are human beings "with feelings, hopes, aspirations, insecurities, worries, strengths, and weaknesses" (Knowles 1975: 33). Knowles emphasises the need for helping students develop "the skills of inquiry" and "the ability to go on acquiring new knowledge easily and skilfully the rest of his or her life" (Knowles 1975: 15-16). Autonomous, self-directed learning can contribute to student readiness to apply their personal agency in their future working environment.

Reflective approaches to translator training require inviting students to reflect and self-reflect with a view to increasing their individual autonomy and selfdiscovery. Reflection can be considered the primary source of the learner transformation, for example in approaches such as experiential learning (Schön 1983; Mezirow 1990, 1996). Reflective practice often requires no elaborate forms of instruction, but effective communication and quality feedback. Effective communication in the translation classroom depends on the interaction within the translator training environment and involves communicating in a way that fosters self-reflection on the part of the students. Candy et al. (1985: 115) suggests, for instance, "prompting here, probing there, inquiring somewhere else, but all the time encouraging the learners to relive the experience and to express in their own words why they behaved the way they did". In order to ensure effective classroom communication, Klimkowski (2019) lists three factors that need to be considered, i.e. creating a safe space for negotiating ideas, separating the person from the problem to minimise the emotional cost of negotiation and describing behaviours without passing judgements.

Mastering the skill of inquiry can potentially raise translation students' metacognitive awareness. A metacognitive approach to translator training (see 
Pietrzak 2022 forth.) focuses on promoting practical experience in metacognitive regulation of the cognitive processes involved in translation service provision (ibid.). It is metacognition that guides transformative learning, knowledge construction and experience building, as it is "the ability to reflect upon, understand and control one's learning" (Schraw and Dennison, 1994). With the teacher's guidance, students' personal resources can be activated thanks to slight modifications to the learning process, regarding, for instance, communication or feedback patterns (see Pietrzak 2022 forth.). Focusing on activating personal resources and fostering their metacognitive skills such as self-regulation, selfassessment, self-reflection and self-feedback appears necessary for students to succeed in efficient functioning in the fast-changing translation market.

\section{Role of technology in trainee-trainer relationship}

The activation of personal resources is of paramount importance in the context of translation technology (see Pietrzak and Kornacki, 2020), utilised both in the translation classroom and translator's workshop. Current developments in translator-oriented IT demand the development of students' self-awareness (in terms of already possessed skills), technological flexibility (ibid.), and learner autonomy. The task of the trainer is difficult in such a context for s/he has to navigate between the role of an instructor - teaching how to apply technology in the translation process (see, for example, Kornacki, 2018) - and that of a mentor who shows how to utilise already possessed skills in new environments and how to transfer those skills to new tools (ibid.).

The Covid-19 pandemic has made the lives of translation trainers even harder. Safety precautions forced extended periods of home office, thus resulting in a transition to online translation training environments (see Kornacki and Pietrzak, 2021), which had to replace traditional classrooms, while fulfilling the same roles. Trainers found themselves in a new situation that required them to help their students develop not only translation-related skills, but also support them psychologically throughout the enforced periods of distance learning, thus strengthening their role as mentors. Technology, previously feared and frequently unheard of in the translation classroom, has become a fully-fledged medium of communication that allows for learning, exchanging information, thoughts, ideas, and social support between trainers and students. However, it is important to draw a line between translation technology (see Pietrzak and Kornacki, 2020) and technology used to train translators. The first one could be referred to as utility technology, involving all the tools that enable or facilitate the translation process. Technology used to train translators involves digital conferencing software, used in university training.

In mid-2020 most people hoped that the Covid-19 pandemic will be over by the end of the year. At the end of 2021, there seems to be no foreseeable end to 
the pandemic. Brief respite from distance learning ends as more and more courses have to move online; such a form of teaching magnifies the effect of online classroom. Hawkins (2021: 75) claims that "[c]lass size has never mattered more. Small translation workshop-style classes seem to work even better than before, but slightly larger reading-based seminars seem doomed since it's hard to build a sense of solidarity in the classroom." The distance between the student and the trainer in a digital classroom is relative. On the one hand, the classroom may feel more intimate when working in a small group since everyone is close to their camera. On the other, it is impossible to 'sneak'n'peak' around the classroom, supporting students when needed. On top of that, not everyone has access to broadband and a camera, which may cause some individuals to feel excluded.

The exclusion should not be regarded only in terms of student exclusion as the whole idea of a virtual classroom is based on everyone participating and sharing their camera feeds. Sadly, it is not always the case and it is not uncommon for the trainers to suffer when involved in a course with no interaction from the students, who claim that they have no means to actively participate from home. While that may be the case in some circumstances, it may be an indication of anxiety of technology as used in the online classroom. Reports from some of the students (received in our personal communication) suggest that the idea of having their face seen close up by other people, combined with the need to vocalise their thoughts while everyone is supposed to pay close attention over the conferencing software, is very stressful, thus resulting in a complete denial and refusal to participate.

Technology and translation can no longer be separated, but it does not mean it is a happy relationship. On the one hand, it facilitates the translation process, but on the other, the amount of potential stress involved in learning how to utilise technology in the translation process (as well as all the extra-translation activities required) can be staggering, especially for students. In order to understand how technology can affect the trainee-trainer relationship. it is paramount to explore the difference between the mindsets of freelance translators and students which we can call professional and learner mindsets, respectively.

The professional mindset, meaning that of a professional (freelance) translator (and translation trainer, in most cases ${ }^{1}$ ), is focused on the task at hand, utilising all available resources (or seeking new ones) in order to complete that task. Those resources include (but are not limited to) technology in all of its forms. The professional mindset leaves no room for doubt or anxiety as the translator knows that the resource in question has to be utilised to assure his/her competitiveness on the market. Technology is a tool to be used and exploited, not to be feared.

The learner mindset is task-oriented as well, but with a much higher degree of uncertainty and anxiety. The (translation) learner is less confident about his/her translation skills and, in contrast to translation professionals, more prone to be

1 Translator training is highly vocational in its nature, therefore it requires translation practitioners to train future translators in order to assure their success. 
anxious about their perception by their peers. In their case, technology is yet another stratum of skills that need to be mastered, resulting in additional stress when its use has to be performed in public. Unlike professionals, students are less focused on the goal and more on the process, and on how they are perceived. Even though they are (technically) young adults, their desire for peer acceptance, and fear of embarrassment in some cases, is still strong.

The relationship between the trainer and the trainee has never been an easy one. There has been ongoing debate (see, for example, Boyd and Myers 1988, González-Davies 2004; Kelly 2005; Kiraly 1995, 2000; Klimkowski 2015, Massey et al. 2019, Kornacki and Pietrzak 2021) how to change that, how to empower the trainee to benefit the most from the offered translation courses. The role of the trainer has shifted from that of an instructor to that of a mentor who suggests, hints, puts a student on the right track, and helps to build students' selfconfidence, self-perception and self-efficacy. Technology can help with that, but it has to be employed with care lest it causes damage. With distance learning becoming a new reality, there is no going back - technology has to be employed on a number of levels, both as a translation facilitating software and as a platform to conduct courses in the first place. Trainers have to realise that communication problems they face daily can be multiplied in the case of students and, as a result, they have to work even harder to develop a strong sense of self in their students (see Haro-Soler and Kiraly 2019, Pietrzak 2022). It will, in turn, allow them to participate and benefit from courses without the fear of using the computer/technology in public and without being anxious about peer acceptance.

\section{Aims and scope of the special issue}

Given that learning is much more important than training, the importance of activating students to be empowered participants of their own learning process cannot be overestimated. This special issue is therefore fully centered around the issues related to the trainees' development and functioning in the translation market. In light of the market demands and pressures on an already limited curriculum, the hope that translator teachers can fully prepare their students for awaiting challenges is somewhat illusory. Market volatility and automation lead to many changes. The customary tasks in the translation profession can be replaced by new, yet unknown ones, to which translators have to efficiently adapt in order to stay on the translation market.

This special issue aims to explore various approaches to translator training with particular attention to the translation trainee. This collection brings together a selection of research-based and practice-oriented perspectives on the topic area. The issue opens with Student Agency in Translator Training. Setting a Framework for Good Practices by Maria González Davies (University Ramon Llull, Spain) who begins by proposing a combined approach for facilitating the development of 
autonomous strategic learning in collaborative and situated environments. The article explores the concept of student agency as the process through which learners become capable of strategic actions that form the basis for autonomy and confidence in their own proficiency and effectiveness.

In the second article, Developing Manageable Individualised Formative Assessment of Trainees Through Rubrics, Catherine Way (University of Granada, Spain) shows the value of rubrics in developing manageable, individualised formative assessment of trainees which makes allowances for a vast range of complex processes that must be assessed, including trainees' planning, monitoring, regulating, evaluating, etc. The author proposes how to counterbalance the multiple demands of trainee assessment, whilst also addressing the time constraints on trainers and the opinions of trainees.

In the third article, Design Thinking as a Tool for Participatory and Transformative Translator Education, Katarzyna Klimkowska (Maria CurieSkłodowska University in Lublin, Poland) and Konrad Klimkowski (Catholic University of Lublin, Poland) advocate using Design Thinking methodology as a structured scaffolding to improve classroom communication. Driven by constructivist, collaborative and participatory approaches, the authors argue that this methodology helps train qualities and skills that are particularly beneficial for students of translator education programmes.

The fourth article, by Sonja Kitanovska-Kimovska and Vladimir Cvetkoski (Ss. Cyril and Methodius University, the Republic of North Macedonia) explores The effect of emotions on translation performance. The authors aim to demonstrate the impact of positive and negative emotions on the overall translation performance and on different aspects of translation performance, as well as the role of the personality trait of resilience in regulating negative emotions.

In the fifth article, Teachers' feedback and trainees' confidence: do they match?, María del Mar Haro Soler (University of Granada, Spain) focuses on one teaching practice, teachers' feedback, and on a students' form of self-perception, self-efficacy beliefs, both inherent to the teaching-learning process, whether it occurs in the classroom or a virtual environment.

In the last article, From deliberate to mindful practice. How work placement contributes to developing expertise in translators, Agata Sadza (University of Łódź, Poland) explores ways in which work placement may contribute to stimulating trainee translators' professional development. The author suggests how deliberate practice may be implemented as one of the significant elements of translation work placement in a student-centred course of translator training.

The knowledge that the special issue offers comes from exploring the developments of translator training in many educational contexts. The stakeholders in translator education can find this collection useful for the analysis and design of translator training practices in the light of recent challenges. 


\section{References}

Boyd, Robert . D., and Myers, Gordon. J. 1988. “Transformative Education.” International Journal of Lifelong Education, 7(4), 261-284.

Candy, Philip, Harri-Augstein Sheila, and Thomas, Laurie (1985). "Reflection and the selforganized learner: a model of learning conversations." In David Boud, Rosemary Keogh, and David Walker, Reflection: Turning Experience into Learning, 100-116. London: Kogan Page.

Cranton, Patricia. 1994. Understanding and Promoting Transformative Learning: A Guide for Educators of Adults. San Francisco: Jossey-Bass.

González-Davies, Maria 2004. Multiple Voices in the Translation Classroom. Activities, Tasks and Projects. Amsterdam \& Philadelphia: John Benjamins.

Gonzalez-Davies, Maria \& Enriquez Raído, Vanessa. (eds) 2018. "Situated learning in translator and interpreter training: Bridging research and good practice." The Interpreter and Translator Trainer, 12-28. 10. 1-11.

Hawkins, Spencer John. 2021. "The Digital Translation Classroom: Another Day at the Computer for the Burgeoning Translato." New Voices in Translation Studies 24: 72-81

Haro-Soler, Maria and Kiraly, Don. 2019. "Exploring self-efficacy beliefs in symbiotic collaboration with students: an action research project". The Interpreter and Translator Trainer 13(3), 255-270, DOI: 10.1080/1750399X.2019.1656405

Kelly, Dorothy 2005. A Handbook for Translator Trainers: A Guide to Reflective Practice, Manchester: St. Jerome.

Kiraly, Don. 1995. Pathways to Translation: Pedagogy and Process. Kent: Kent State University Press.

Kiraly, Don. 2000. A Social Constructivist Approach to Translator Education. Empowerment from $\neg$ Theory to Practice, Manchester, St. Jerome.

Klimkowski, Konrad. 2015. Towards a Shared Curriculum in Translator and Interpreter Education, Wrocław: Wydawnictwo Wyższej Szkoły Filologicznej.

Knowles, Malcolm. 1975. Self-directed learning: A guide for learners and teachers, New York, Toronto: Cambridge Adult Education Company.

Kornacki, Michał. 2018. Computer-assisted translation (CAT) tools in the translator training process. Peter Lang.

Kornacki, Michał and Paulina Pietrzak. 2021. "New translator training environments: Towards improving translation students' digital resilience". New Voices in Translation Studies 24 Special Issue.

Massey, Gary, Don Kiraly and Maureen Ehrensberger-Dow (eds.). 2019. The Interpreter and Translator Trainer, 13(3), Special issue: Training the Trainers.

Mezirow, Jack. 1990. "How critical reflection triggers transformative learning." In Jack Mezirow (ed.)., Fostering Critical Reflection in Adulthood: A Guide to Transformative and Emancipatory Education, 1-20. San Francisco: Jossey-Bass.

Mezirow, Jack. 1996. "Contemporary paradigms of learning." Adult Education Quarterly, 46(3): 158-173. https://doi.org/10.1177/074171369604600303

Mezirow, Jack. 2003. "Transformative Learning as Discourse.” Journal of Transformative Learning $1(1), 58-63$.

Pietrzak, Paulina and Kornacki, Michał 2020. Using CAT Tools in Freelance Translation: Insights from a Case Study, New York: Routledge.

Pietrzak, Paulina. 2022 forth. Metacognitive translator training: focus on personal resources. London: Palgrave.

Schön, Donaldr, A. 1983. The Reflective Practitioner: How Professionals Think in Action. New York: Basic Books. 